\title{
Ultrasonic removal efficacy of calcium hydroxide inside root canal walls with different power rating and activation time protocols
}

\begin{abstract}
The objective of this study is to evaluate the ultrasonic efficiency to remove calcium hydroxide from the root canal walls, with different power rating and activation time protocols. Material and Methods: Extracted single rooted premolars were instrumented with Twisted File \#40/.04. Each canal was filled with $\mathrm{Ca}(\mathrm{OH})_{2}$, and all specimens were stored in $37^{\circ} \mathrm{C}$ at $100 \%$ relative humidity for 1 week. The specimens were aleatory distributed in to nine experimental groups ( $\mathrm{n}=20)$, as follows: G10x10; G10x20; G10x30; G20x10; G20x20; G20x30; G30x10; G30x20; G30x30; where the first value corresponds to the power rating (in \%), and the second value corresponds to the activation time (in s) of the ultrasonic tip (Irrisonic, Helse). The specimens were observed under a scanning electron microscope and the $\mathrm{Ca}(\mathrm{OH})_{2}$ amount was calculated by scores. Data were statistically analyzed by 2-way ANOVA and Tukey post-test. Results: G20X20 and G30X30 were significantly more efficient to remove $\mathrm{Ca}(\mathrm{OH})$, than the other groups $(\mathrm{p}<0.05)$, without significant differences between them. Conclusion: $20 \%$ of power rating with 20 seconds, and $30 \%$ of power rating with 30 seconds were more efficient to remove $\mathrm{Ca}(\mathrm{OH})_{2}$ from the root canal walls.
\end{abstract}

Keywords: calcium hydroxide, irrigation, removal, ultrasonic
Volume I0 Issue I - 2019

\author{
Leslie Pamela de la Cruz Macedo,' Renzo \\ Nazario Riquero,' Renzo Vertiz Falla, ${ }^{2}$ \\ Osnara Maria Mongruel Gomes, ${ }^{3}$ Bruna \\ Fortes Bittencourt, ${ }^{3}$ John Alexis Dominguez \\ 'Department of Endodontics, Faculty of Dentistry, Norbert \\ Wiener University, Peru \\ 2Department of Endodontics, Faculty of Dentistry, UPC, Peru \\ ${ }^{3}$ Department of Dentistry, State University Ponta Grossa, Brazil
}

Correspondence: John Alexis Dominguez, Department of Endodontics, Faculty of Dentistry, Norbert Wiener University, Arequipa 440,Lima, Peru, Tel 51949725703 ,

Email johnalexis.dominguez@gmail.com

Received: January II, 2019 | Published: January 23, 2019

\section{Introduction}

The main objectives in endodontic therapy are disinfection and complete obturation of the root canal system. ${ }^{1}$ The disinfection may be obtained by chemo-mechanical preparation; however, clinical circumstances require the use of intracanal medication (ICM) when the endodontic treatment is performed in more than one session. ${ }^{2}$ Calcium hydroxide $\left(\mathrm{Ca}(\mathrm{OH})_{2}\right)$ is the most commonly used intracanal medication (ICM) due to its antibacterial efficiency ${ }^{3,4}$ and biocompatibility. ${ }^{5}$ However, $\mathrm{Ca}(\mathrm{OH}) 2$ accelerates the setting time of endodontic cements and sealers that are used to obturate the canals. This is probably due to inadequate $\mathrm{Ca}(\mathrm{OH}) 2$ removal from the canal walls, ${ }^{6}$ which obliterate dentinal tubules ${ }^{7}$ and would result in poor-quality obturation. ${ }^{8}$ Authors also evaluated the microleakage in root canal walls medicated with and without $\mathrm{Ca}(\mathrm{OH})_{2}$, and they concluded that the ones which received ICM demonstrated the highest microleakage scores.

One study evaluated the use of passive ultrasonic irrigation (PUI) to remove $\mathrm{Ca}(\mathrm{OH})$, in the root apical third, compared to conventional irrigation needle delivery. The results showed that PUI was significantly superior than the conventional needle delivery system. ${ }^{10}$ When comparing the needle delivery technique to passive ultrasonic activation and negative pressure (i.e.-EndoVac), better results were attributed to EndoVac. Similar results were obtained with constant, passive ultrasonic activation for one minute. ${ }^{11}$ However, in the mentioned studies they do not have a standardized time and power ratings protocol for the use of ultrasonic passive irrigation, which makes it difficult to compare them and establish an adequate protocol to use by clinicians. Considering the current controversial results in the literature regarding adequate root canal disinfection protocol, the objective of this study is to evaluate the ultrasonic removal efficiency of $\mathrm{Ca}(\mathrm{OH})_{2}$ along the root canal walls using different ultrasonic activation times and power ratings.

\section{Material and methods}

The protocol was approved by the Ethics Committee Norbert Wiener Private University. Single rooted premolars were extracted from patients at the University Norbert Wiener Private University (Lima-Perú), ultrasonically cleaned and stored in distilled water at $4^{\circ} \mathrm{C}$. They were used within six months after their extraction. Teeth that exhibited clinical signs of dental caries, root resorption, cracks, or fractures were excluded, and they were radiographed to confirm their single-rooted anatomy. Additionally, using a diamond saw (MDT, Afula, Israel) under constant irrigation each sample was decoronated in order to obtain a standardized root length of $15 \pm 2 \mathrm{~mm}$ from the apex.

The patency of the canals was verified by a $15 \mathrm{~K}$-file (SybronEndo, Orange, California, USA) passing through the apical foramen, and the working length was determined to be $1 \mathrm{~mm}$ short of the total length of each tooth. A crown-down instrumentation technique (Twisted Files, SybronEndo, Orange, California, USA) was implemented in each sample tooth by enlarging the canal until 40.04 file, according to the manufacturer's instructions, in a reciprocating motion (VDW Silver Reciproc handpiece, VDW, Germany). The root canals were irrigated between each rotary file using NaviTip ${ }^{\circledR}$ (Ultradent Products, South Jordan, UT, USA) positioned $1 \mathrm{~mm}$ short of the working length with $1.0 \mathrm{ml}$ of a $5.25 \% \mathrm{NaOCl}$ and $1.0 \mathrm{ml}$ of $17 \%$ EDTA solutions. After drying the canals with paper points, each canal was filled with $\mathrm{Ca}(\mathrm{OH})_{2}$ (UltraCal XS, Ultradent Products, South Jordan, UT, USA), except the negative controls. The presence of $\mathrm{Ca}(\mathrm{OH})_{2}$ in the root canals was confirmed with mesiodistal and buccolingual radiographs. The root access was temporarily filled with Coltosol ${ }^{\circledR} \mathrm{F}$ (Coltene, Altstätten, Swiss). The specimens were stored for 7 days at $37^{\circ} \mathrm{C}$ and $100 \%$ humidity.

After the storage period, the temporary restoration was removed, and the specimens were randomized in three experimental groups 
$(\mathrm{n}=20)$, according to the power rating and activation time of the ultrasonic tip used to remove the medication: G10x10; G10x20; G10x30; G20x10; G20x20; G20x30; G30x10; G30x20; G30x30. The first value corresponds to the power rating (in\%), and the second value corresponds to the activation time (in s) of the ultrasonic tip. Each group had one specimen for positive control (no $\mathrm{Ca}(\mathrm{OH})_{2}$ was removed), and one specimen for negative control (the canal was completely filled by $\left.\mathrm{Ca}(\mathrm{OH})_{2}\right)$. In all protocols, the roots were irrigated with $1 \mathrm{ml}$ of $5.25 \% \mathrm{NaOCl}$. The working length was checked (Twisted Files, 40/.04), and the ultrasonic tip (Irrissonic, Helse, Santa Rosa de Viterbo, SP, Brazil) was used with the ultrasonic unit VDW.ULTRA ${ }^{\circledR}$ (VDW, Germany) to continuously irrigate the canals with $3.0 \mathrm{ml}$ of $5.25 \% \mathrm{NaOCl}, 2 \mathrm{~mm}$ short of the working length. During activation, the needle was passively moved in an up-and-down motion to ensure it did not bind to the root canal wall. A final rinse with $1.0 \mathrm{ml}$ of $17 \%$ EDTA and $3.0 \mathrm{ml} 0.5 \% \mathrm{NaOCl}$ ended the irrigation protocol. After irrigation protocols, the specimens were longitudinally sectioned in a buccal and lingual direction with a diamond saw (Medin, Vlachovická, Czech Republic), and care was taken to avoid contact between the saw and the root canal surface. The specimens were separated into halves with a chisel.

\section{Scanning Electron Microscopy (SEM)}

The specimens were dehydrated for 48 hours in a desiccator (Dry Keeper Simulate Corp., Tokyo, Japan), and sputter coated with a 10 nm platinum layer (Polaron Equipment Ltd., Hertfordshire, England, UK). SEM analyzes were performed under $1000 \mathrm{X}$ magnification in the middle third. The root canal wall area was calculated in order to evaluate the residual $\mathrm{Ca}(\mathrm{OH})_{2}$ amount. Using the scoring system previously described by Yücel ${ }^{11}$ and Alturaki, ${ }^{12}$ three calibrated investigators made the evaluations. Each canal was scored as follows:

Score 1: $80-100 \%$ of $\mathrm{Ca}(\mathrm{OH})_{2}$ removal: dentinal tubules were considered totally cleaned; dentinal tubules inside root walls may be totally visualized without the presence of any $\mathrm{Ca}(\mathrm{OH})_{2}$ amount (Figure 1A)

Score 2: $60-80 \% \mathrm{Ca}(\mathrm{OH})$, removal: adequate cleaned; dentinal tubules inside root walls may be visualized, and there is minimal $\mathrm{Ca}(\mathrm{OH})_{2}$ amount on the canal walls (Figure 1B).

Score 3: $40-60 \% \mathrm{Ca}(\mathrm{OH})_{2}$ removal: partially cleaned, and at least $50 \%$ of the dentinal tubules surface was covered with $\mathrm{Ca}(\mathrm{OH})_{2}$ (Figure 1C).

Score 4: $20-40 \% \mathrm{Ca}(\mathrm{OH})_{2}$ removal: was considered poorly cleaned, the dentinal tubules along the canal walls may not be visualized, and there is a heavy presence of $\mathrm{Ca}(\mathrm{OH})_{2}$ amount (Figure 1D).

Score 5: 0-20\% $\mathrm{Ca}(\mathrm{OH})$, removal: not cleaned, dentinal tubules inside the root canal walls are totally obliterated by the $\mathrm{Ca}(\mathrm{OH})_{2}$ medication (Figure 1E).

The mean scores were used for statistical purposes. Data was statistically analyzed by 2 -way ANOVA and Tukey post-test $(\alpha=0.05)$.

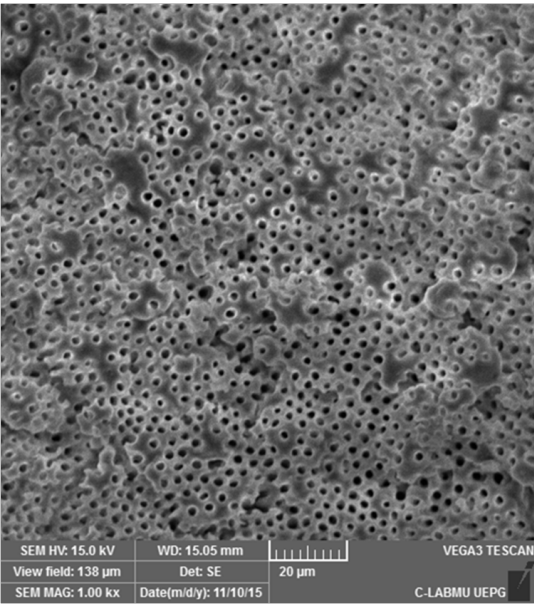

(A)

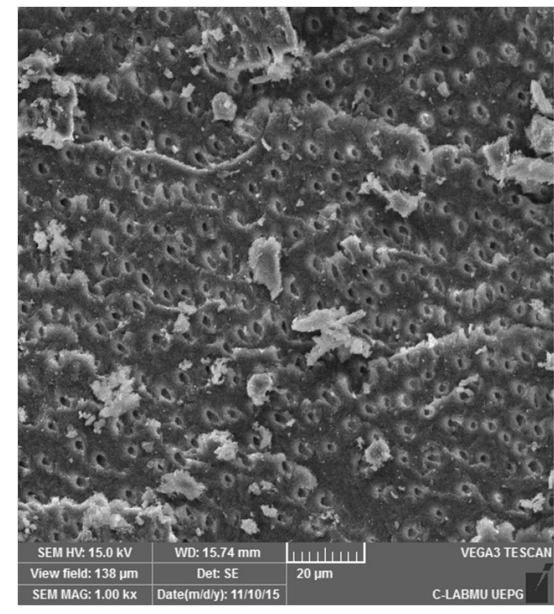

(B)

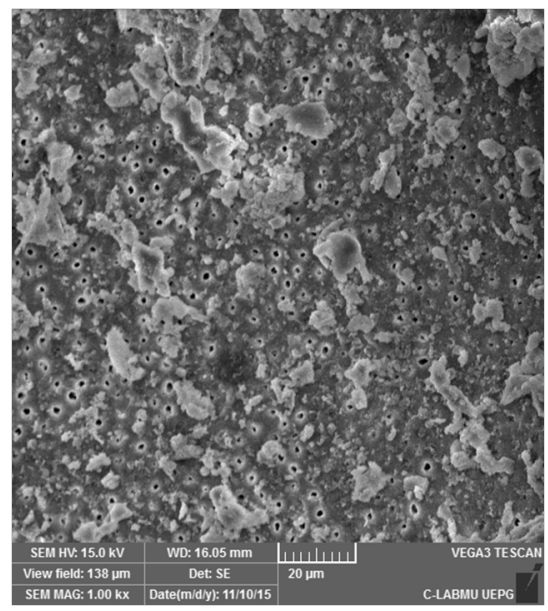

(C)

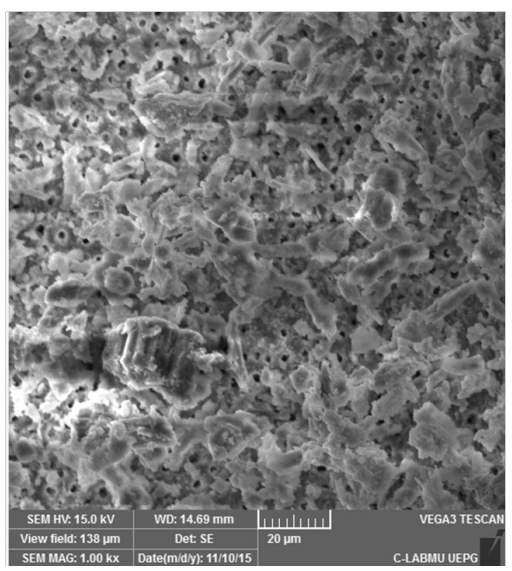

(D)

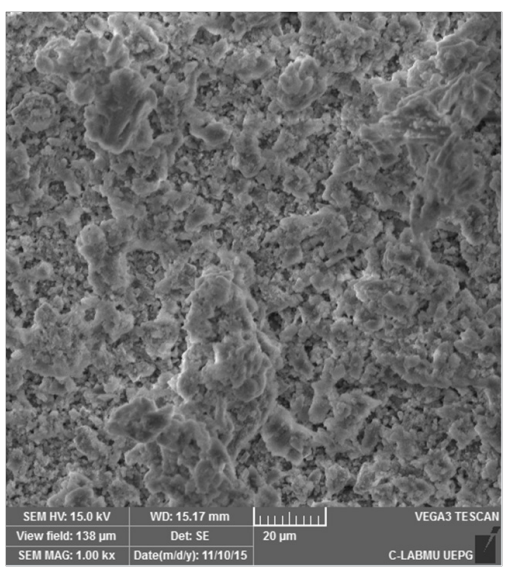

(E)

Figure I Scanning electron microscopic images representative of score attribution. (A) score I: $80 \%-100 \% \mathrm{Ca}(\mathrm{OH})_{2}$ removal (totally cleaned); (B) score 2 : $60 \%-80 \% \mathrm{Ca}(\mathrm{OH})_{2}$, removal (adequate cleanliness); (C) score 3: $40 \%-60 \%$ of $\mathrm{Ca}(\mathrm{OH})$, removal (partial cleanliness); (D) score $4: 20 \%-40 \%$ of $\mathrm{Ca}(\mathrm{OH}){ }_{2}$ removal (poorly cleanliness), and (E) score $5: 0 \%-20 \%$ of $\mathrm{Ca}(\mathrm{OH})_{2}$ removal (not cleaned).

Citation: Macedo LPC, Riquero RN, Falla RV, et al. Ultrasonic removal efficacy of calcium hydroxide inside root canal walls with different power rating and activation time protocols. J Dent Health Oral Disord Ther. 2019;10(I):59-62. DOI: I0.15406/jdhodt.2019.10.00460 


\section{Results}

Positive controls demonstrated score 5, with dentinal tubules completely covered by $\mathrm{Ca}(\mathrm{OH})_{2}$ (Figure $1 \mathrm{E}$ ). For the negative controls, score 1 was attributed for all specimens (Figure 1A). Table 1 describes mean and standard deviation of the obtained scores evaluated by SEM. The lowest scores were observed when the ultrasonic tip was used with a $20 \%$ power rating for 20 seconds $(1.93 \pm 1.09)$ and with a $30 \%$ power rating for 30 seconds $(2.58 \pm 1.33)$, being statistically different from the other groups $(\mathrm{p}<0.05)$. The other groups did not show any differences between them.

Table I Mean and standard deviation of the scores obtained in each experimental group*

\begin{tabular}{llll}
\hline & $10 \mathrm{~s}$ & $20 \mathrm{~s}$ & $30 \mathrm{~s}$ \\
\hline $10 \%$ & $4.08 \pm 1.12 \mathrm{~B}$ & $3.61 \pm 1.27 \mathrm{~B}$ & $4.11 \pm 1.07 \mathrm{~B}$ \\
$20 \%$ & $4.41 \pm 0.78 \mathrm{~B}$ & $1.93 \pm 1.09 \mathrm{~A}$ & $3.29 \pm 1.24 \mathrm{~B}$ \\
$30 \%$ & $3.67 \pm 0.87 \mathrm{~B}$ & $4.34 \pm 0.85 \mathrm{~B}$ & $2.85 \pm 1.33 \mathrm{~A}$ \\
\hline
\end{tabular}

*Distinct letters demonstrated statistically significant differences $(p<0.05)$

\section{Discussion}

The presence of $\mathrm{Ca}(\mathrm{OH})_{2}$ may influence the physical properties of sealers such as working time and set thickness. ${ }^{13}$ Also, there is a significant reduction in the bond strength of resin-based sealers due to $\mathrm{Ca}(\mathrm{OH})_{2}$, amount which covers the dentin/collagen network that is necessary for the resin adherence. ${ }^{14}$ Goldberg evaluated how $\mathrm{Ca}(\mathrm{OH})_{2}$ obliterate lateral canals hindering the obturation with the sealer. The results revealed that the negative control group (with no $\mathrm{Ca}(\mathrm{OH})_{2}$ amount) had a significantly higher number of adequately obturated lateral canals $;{ }^{15}$ therefore, it seems important to remove as much $\mathrm{Ca}(\mathrm{OH})_{2}$ as possible from the root canal before the obturation.

Among several irrigating protocols, the frequency of the early ultrasonic units ranged from 25 to $40 \mathrm{kHz}$. Irrigation frequencies are currently recommended to be used at a higher frequency than that of human hearing or $20 \mathrm{kHz} .{ }^{16}$ Ultrasonics has been widely used in the cleaning of the root canal. Authors have compared the debris removal efficacy between the manual and rotatory preparation with and without ultrasonic activation. An ex-vivo study histologically analyzed the extracted teeth and concluded that the ultrasonic activation improved cleaning efficacy in mesial roots of lower molars. ${ }^{17}$ The use of the scanning electron microscope and score scale, used in this study, to evaluate the $\mathrm{Ca}(\mathrm{OH})_{2}$ removal from the root canal walls, has been described in previous studies such Yücel ${ }^{11}$ and Alturaki. ${ }^{12}$ In these respective studies, the authors evaluated different final irrigation techniques and demonstrated that no irrigating protocols were able to completely remove the $\mathrm{Ca}(\mathrm{OH})_{2}$ medication from the root canal walls, which is similar to the results of the present study. The same results found for negative and positive controls were found in the present study, where positive control were totally obliterated by the $\mathrm{Ca}(\mathrm{OH})$ medication and negative control were totally visualized without the presence of any $\mathrm{Ca}(\mathrm{OH})_{2}$ amount. ${ }^{11,12}$

Other study showed that rotatory instrumentation combined with passive ultrasonic activation (3-20 s sessions) demonstrated small $\mathrm{Ca}(\mathrm{OH})_{2}$ amounts when compared to sonic irrigation. ${ }^{18}$ In the present study, the lowest scores were observed when the ultrasonic tip was used 3 times during $20 \mathrm{~s}$. In other study, the following protocols were studied: passive ultrasonic irrigation, the common irrigating syringe, EndoVac and self-adjustable files to remove $\mathrm{Ca}(\mathrm{OH})_{2}$. Better results were found when the irrigants were continuously agitated using a $\# 15$
K-file coupled to the file-holding adapted handpiece and when the ultrasonic tip was activated at the sixth power setting of power setting available in that unit, as well as with the self-adjustable files. ${ }^{19}$

During this study, it was only evaluated the amount of $\mathrm{Ca}(\mathrm{OH})_{2}$ in the middle third. Other studies demonstrated no benefit in the passive irrigation used to remove $\mathrm{Ca}(\mathrm{OH})_{2}$ from the apical third. Comparing two techniques (manual and passive ultrasonic irrigation), and using four different methods to prepare the $\mathrm{Ca}(\mathrm{OH})_{2}$ mix, researchers found a significant $\mathrm{Ca}(\mathrm{OH})_{2}$ removal using passive irrigation in the cervical and middle thirds of the canal. However, they found no differences in the apical third. ${ }^{20}$

The improved irrigation of ultrasonic tips is due in part to cavitation, which is defined as the formation of small bubbles that are created and rapid explode. This explosion may promotes a cleansing "shock wave" within the irrigation solution, which produces a forceful energy that aids in debris removal from the instrumented canal walls. ${ }^{21}$

There is no consensus in the literature regarding a specific protocol when using ultrasonic tips in root canal spaces. Moreover, the duration of the required activation time is not clear. Researchers found higher debris removal with a 5-min activation when compared to $3 \mathrm{~min},{ }^{22}$ however, no differences were found in another study which used ultrasonic irrigation with 30 and $60 \mathrm{~s}$ of activation. ${ }^{23}$

Higher power setting does not necessarily produce more effective $\mathrm{Ca}(\mathrm{OH})_{2}$ removal, and this may be due to the fact that when power is increased, the cavitation bubbles that are produced may not successfully perform the mechanical action in which they are intended. Also, it was found that although the experimental group using a $30 \%$ power for 30 s successfully removed $\mathrm{Ca}(\mathrm{OH})_{2}$ this group showed micro-fractures within the dentinal tubules, which is confirmed by other study ${ }^{24}$ that the use of prolonged activation times may result in microfractures of the root canal walls. Consideration should be given in this study for the fact that the teeth were decoronated, which causes a loss of the irrigation solution coronally, thus, decreasing the hydrostatic pressure towards the ápex. ${ }^{12,18}$

\section{Conclusion}

Under the aspects of this study, none of the groups demonstrated complete removal of $\mathrm{Ca}(\mathrm{OH})_{2}$ from the root canal walls. However, the use of an ultrasonic tip with $20 \%$ power setting for $20 \mathrm{~s}$, or the use of $30 \%$ power setting for 30 s were more efficient to remove $\mathrm{Ca}(\mathrm{OH})_{2}$ from the canal walls.

\section{Acknowledgments}

None.

\section{Conflicts of interest}

The author declares that there is no conflict of interest.

\section{References}

1. Coldero LG, McHugh S, MacKenzie D, et al. Reduction in intracanal bacteria during root canal preparation with and without apical enlargement. Int Endod J. 2002;35:437-446.

2. Su Y, Wang C, Ye L. Healing Rate and Post-obturation Pain of Singleversus Multiple-visit Endodontic Treatment for Infected Root Canals: A Systematic Review. JOE. 2011;37(2):125-132.

3. Tanomaru Filho M, Leonardo MR, Bezerra da Silva LA. Effect of Irrigating Solution and Calcium Hydroxide Root Canal Dressing on the Repair of Apical and Periapical Tissues of Teeth with Periapical Lesion. JOE. 2002;28:295-299. 
4. Siqueira JF, Lopes HP. Mechanisms of antimicrobial activity of calcium hydroxide: a critical review. Int Endod Jl. 1999;32(5):361-369.

5. Athanassiadis B, Abbott PV, Walsh LJ. The use of calcium hydroxide, antibiotics and biocides as antimicrobial medicaments in endodontics. Aust Dent J. 2007;52(1 Suppl):S64-S82.

6. Margelos J, Eliades G, Verdelis C, et al. Interaction of calcium hydroxide with zinc oxide-eugenol type sealers: a potential clinical problem. JOE. 1997;23(1):43-48

7. Calt S, Serper A. Dentinal tubule penetration of root canal sealers after root canal dressing with calcium hydroxide. J Endod. 1999;25(6):431-433.

8. Vilela DD, Neto MM, Villela AM, et al. Evaluation of interference of calcium hydroxide-based intracanal medication in filling root canal systems. The Journal of Contemporary Dental Practice. 2011;12:368-371

9. Kim SK, Kim YO. Influence of calcium hydroxide intracanal medication on apical seal. Int Endod J. 2002;35:623-628.

10. van der Sluis LM, Versluis M, Wu MK, et al. Passive ultrasonic irrigation of the root canal: a review of the literature. Int Endod J. 2007;40(6):415-426.

11. Yücel AC, Gürel M, Güler E. Comparison of final irrigation techniques in removal of calcium hydroxide. Aust Endod Jl. 2011;39(3):116-121

12. Alturaiki S, Lamphon H, Edrees H, et al. Efficacy of 3 Different Irrigation Systems on Removal of Calcium Hydroxide from the Root Canal: A Scanning Electron Microscopic Study. Journal of Endodontics. 2015;41(1):97-101.

13. Hosoya N, Kurayama H, Iino F, et al. Effects of calcium hydroxide on physical and sealing properties of canal sealers. Int Endod J. 2004;37(3):178-184.

14. Barbizam JV, Trope M, Teixeira EC, et al. Effect of calcium hydroxide intracanal dressing on the bond strength of a resin-based endodontic sealer. Braz Dent J. 2008;19(3):224-227.
15. Goldberg F, Artaza LP, De Silvio AC. Influence of Calcium Hydroxide Dressing on the Obturation of Simulated Lateral Canals. JOE. 2002;28(2):99-101.

16. Plotino $\mathrm{G}$, Pameijer $\mathrm{CH}$, Maria Grande $\mathrm{N}$, et al. Ultrasonics in Endodontics: A Review of the Literature. JOE. 2007;33(2):81-95.

17. Gutarts R, Nusstein J, Reader A, et al. In Vivo Debridement Efficacy of Ultrasonic Irrigation Following Hand-Rotary Instrumentation in Human Mandibular Molars. JOE. 2005;31(3):166-170.

18. Wiseman A, Cox TC, Paranjpe A, et al. Efficacy of Sonic and Ultrasonic Activation for Removal of Calcium Hydroxide from Mesial Canals of Mandibular Molars: A Microtomographic Study. J Endod. 2011;37(2):235-238

19. Capar ID, Ozcan E, Arslan H, et al. Effect of Different Final Irrigation Methods on the Removal of Calcium Hydroxide from an Artificial Standardized Groove in the Apical Third of Root Canals. JOE 2014;40(3):451-454

20. Balvedi RA, Versiani MA, Manna FF, et al. A comparison of two techniques for the removal of calcium hydroxide from root canals. Int Endod J. 2010;43(9):763-768.

21. van der Sluis LM, Wu MK, Wesselink PR. The evaluation of removal of calcium hydroxide paste from an artificial standardized groove in the apical root canal using different irrigation methodologies. International Endodontic Journal. 2007;40(1):52-57.

22. Sabins RA, Johnson JD, Hellstein JW. A comparison of the cleaning efficacy of short-term sonic and ultrasonic passive irrigation after hand instrumentation in molar root canals. JOE. 2003;29(10):674-678.

23. Park E. Ultrasonics in endodontics. Endodontic Topics. 2013;29(1):125-159.

24. Cameron JA. The use of ultrasonics in the removal of the smear layer: a scanning electron microscope study. JOE. 1983;9(7):289-292. 